\title{
MỘT SỐ GIẢI PHÁP NÂNG CAO HIỆU QUẢ CôNG TÁC KHẢO SÁT, ĐO ĐẠC VÀ THU THẬP DŨ LIẸU CÁC YẾU TỐ HẢ̇ VĂN TRÊN BIỂN ĐÔNG
}

\author{
DƯO'NG VÂN PHONG ${ }^{(1)}$, KHƯƠNG VĂN LONG(2) \\ (1)Trường Đại học Mỏ - Địa chất \\ ${ }^{(2)}$ Đoàn Đo đạc Biên vẽ hải đồ và Nghiên cứu biển
}

\section{Tóm tắt:}

Bài báo trình bày khái quát về đặc điểm khí tượng, hải văn và công tác khảo sát, đo đạc và thu thập dữ liệu các yếu tố hải văn trên Biển Đông. Trên cơ sở so sánh độ tin cậy của số liệu được lưu trũ trong CSDL với số liệu mói thu thập được, các tác giả đã đề xuất một số giải pháp nhằm nâng cao hiệu quả công tác khảo sát, đo đạc và thu thập dữ liệu các yếu tố hải văn biển.

\section{1. Đặt vấn đề}

Tài nguyên môi trường biển có vai trò đặc biệt quan trọng gắn với chủ quyền, quyền chủ quyền quốc gia, đặc quyền kinh tế và an ninh quốc phòng trên biển, do vậy việc điều tra cơ bản và đo đạc thu thập các yếu tố hải văn là nền tảng vững chắc để tiến ra biển, đưa nước ta trở thành quốc gia mạnh về biển, giàu lên từ biển. Thực hiện Quyết định số 47 của Thủ tướng Chính phủ, trong giai đoạn từ 2006-2012 Bộ Tài nguyên và Môi trường với tư cách là cơ quan thường trực của Đề án 47 đã triển khai cho các cơ quan liên quan tập trung hoàn thành nhiều nhiệm vụ, dự án quan trọng về điều tra cơ bản tài nguyên môi trường biển. Song song với việc thực hiện các nhiệm vụ điều tra cơ bản, chúng ta cũng đạt được nhiều kết quả đáng kể trong việc xây dựng cơ sở dữ liệu biển, đào tạo nguồn nhân lực và hợp tác quốc tế về điều tra cơ bản và quản lý tài nguyên môi trường biển. Do tính chất quan trọng của công tác khảo sát, đo đạc, thu thập dữ liệu các yếu tố hải văn biển nên cần phải tiến hành đồng bộ một số giải pháp để thúc đẩy hơn nữa công tác này trong thời gian tới.

\section{2. Đặc điểm về khí tượng và hải văn của Biển Đông}

Việt Nam là một trong những quốc gia có vùng biển rộng lớn trong khu vực và thế giới với hơn $3.260 \mathrm{~km}$ đường bờ biển,hơn 2.779 đảo lớn nhỏ phân bố trên toàn vùng biển và vùng đặc quyền kinh tế rộng trên 1 triệu km². Với đặc điểm đó, Việt Nam được xếp thứ 27 trong số 157 quốc gia và vùng lãnh thổ có biển trên thế giới về diện tích biển. Tính trung bình cứ $100 \mathrm{~km}^{2}$ đất liền thì có 1 kmbò̀ biển. Trong khi đó trên thế giới trung bình $600 \mathrm{~km}^{2}$ diện tích lục địa mới có $1 \mathrm{~km}$ bờ biển, vì vậy Việt Nam là quốc gia rất lợi thế về biển.

Biển Đông có diện tích khoảng 3.447.000 $\mathrm{km}^{2}$, gấp hơn 8 lần Biển Đen và gần 1.5 lần Địa Trung Hải. Biển Đông bao gồm cả vịnh Bắc Bộ và Vịnh Thái Lan, có độ sâu trung bình $1.140 \mathrm{~m}$. Biển Đông tương đối kín, xung quanh được bao bọc bởi các đảo, quần đảo và đất liền, tuy vậy Biển Đông đều thông với các biển lân cận và các đại dương qua các eo biển. Phía Tây Nam Biển Đông thông ra Ân Độ Dương qua eo Malacca giữa bán đảo Malaysia và đảo Sumatra (Indonesia), phía Nam qua eo Karimata và

\footnotetext{
Ngày nhận bài: 16/6/2017, ngày chuyển phản biện: 19/6/2017, ngày chấp nhận phản biện: 26/6/2017, ngày chấp nhận đăng: 27/6/2017
} 
Biển Giava (Indonesia) đi ra Ấn Độ Dương bằng hai cửa Sunda (giữa Giakacta và Lombok (gần Bali). Phía Bắc và phía Đông của Biển Đông thông với Thái Bình Dương qua các eo biển sâu và các eo biển của quần đảo Philippine (Lê Đức Tố,1999).

Biển Đông quan trọng về chiến lược, giàu về tài nguyên và đa dạng về sinh học, giữ vị trí quan trọng thứ hai trên thế giới sau Địa Trung Hải. Đây là con đường hàng hải quốc tế nối Ấn Độ Dương với Thái Bình Dương, Đông Á với Nam Á và từ đó với các con đường đi về Châu Phi, Châu Âu, đồng thời cũng nằm trong con đường hàng không quan trọng của quốc tế.

Điều kiện khí hậu, chế độ nhiệt, muối và dòng chảy tầng mặt Biển Đông chịu sự chi phối và ảnh hưởng rõ rệt của hai đới gió mùa Đông Bắc và Tây Nam. Vào mùa Đông, khi khối áp cao lục địa phát triển mạnh tạo nên trường gió Đông Bắc thịnh hành trên toàn Biển Đông, kéo theo đó là khối nước có nhiệt độ thấp, độ muối cao ở Thái Bình Dương đẩy vào qua eo biển Đài Loan và lạch Bashi tạo nên lưỡi nước lạnh phát triển sâu xuống phía Nam đến khoảng vĩ độ $5^{\circ} \mathrm{N}$. Do Biển Đông là biển gần kín nên dưới ảnh hưởng của hoàn lưu trung Thái Bình Dương, kết hợp với đới gió mùa Đông Bắc tạo nên hoàn lưu trung Biển Đông, hình thành xoáy thuận có tâm nằm ở trung tâm của biển. Phía bờ Tây giáp vùng biển Nam Trung Bộ dòng thịnh hành có hướng Nam, tốc độ có thể đạt từ $60-70 \mathrm{~cm} / \mathrm{s}$; phía bờ Đông giáp Philippine dòng có hướng Bắc, tốc độ nhỏ hơn bờ Đông. Tương tự, khi trường gió mùa Tây Nam phát triển mạnh (từ tháng 6 - tháng 8 ), một dòng chảy mạnh được hình thành theo hướng Tây Nam Đông Bắc đối nghịch với hoàn lưu Đông Bắc. Phần lớn khối nước của dòng chảy chính đi qua lạch Bashi và nhập vào hải lưu ấm Kurosio ở vùng phát nguyên của nó và một phần nhỏ đi qua eo biển Đài Loan lên phía Bắc. Ở phía Nam, khối nước từ biển
Giava dồn vào Biển Đông không đủ cung cấp cho hải lưu chính nên từ giữa Biển Đông hình thành nghịch lưu chảy theo hướng ngược với hải lưu chính. Vào thời kỳ phát triển mạnh của gió mùa Tây Nam,dòng chảy chính gần bờ biển Nam Việt Nam và phần nửa phía Bắc của biển đạt vận tốc trung bình khoảng $30 \mathrm{~cm} / \mathrm{s}$, cực đại khoảng $50-60 \mathrm{~cm} / \mathrm{s}$.

Chế độ nhiệt lớp nước tầng mặt và giữa của Biển Đông chịu sự chi phối chủ yếu bởi hai đới gió mùa Đông Bắc và Tây Nam. Nhìn chung phạm vi biến động nhiệt độ lớp nước mặt Biển Đông không rộng, biên độ trung bình năm tương đối nhỏ ở phía Nam (khoảng $2-3^{\circ} \mathrm{C}$ ), nhưng tăng dần lên phía Bắc và có thể đạt $12-15^{\circ} \mathrm{C}$. Trong mùa Hè Thu, sự phân bố nhiệt độ nước tầng mặt giữa các vùng trên biển tương đối đồng đều. Tuy nhiên trong tháng 8 , vào thời kỳ thịnh hành của gió mùa Tây Nam, nhiệt độ nước trung bình toàn biển đạt trị số lớn $28^{\circ} \mathrm{C}-29^{\circ} \mathrm{C}$. Khu vực có nhiệt độ cao là Vịnh Bắc Bộ, Vịnh Thái Lan và ven bờ Tây quần đảo Kalimanta. Khu vực có nền nhiệt thấp là vùng nước ven bờ Nam Trung Bộ, giá trị nhiệt độ luôn thấp hơn $27^{\circ} \mathrm{C}$ và có thể đạt giá trị thấp nhất đến $24-26^{\circ} \mathrm{C}$. Nguyên nhân là do hoạt động nước trồi của gió mùa Tây Nam. Trong mùa gió Đông Bắc, sự phân bố nhiệt độ nước trên mặt biển chịu ảnh hưởng rõ rệt của khối không khí lạnh cực đới chuyển về, hình thành các lưỡi nước lạnh với trị số dưới $25^{\circ} \mathrm{C}$, thậm chí dưới $22^{\circ} \mathrm{C}$ ăn sâu xuống phía Tây Nam của biển. Ở vùng biển từ vĩ độ $19^{\circ} \mathrm{N}$ trở lên, trong mùa này gradien nhiệt độ nước đạt giá trị trung bình trên dưới $1^{\circ} \mathrm{C}$ theo mỗi vĩ độ. Ở phía Nam và Đông Nam của biển và Vịnh Thái Lan, nhiệt độ nước biển tầng mặt biến thiên it theo không gian và tương đối ấm, khoảng $25-27^{\circ} \mathrm{C}$ trong tháng 2 và $26-29^{\circ} \mathrm{C}$ trong tháng 11. Có thể nói ở vùng khơi Biển Đông, nhiệt độ nước của lớp bề mặt chịu ảnh hưởng trực tiếp của hai đới gió mùa thông 
qua các quá trình tương tác mạnh biển - khí quyển. Lớp nước mặt đó có bề dày khoảng $30-40 \mathrm{~m}$ trong mùa Hè và khoảng $70-90 \mathrm{~m}$ mùa Đông. Từ khoảng $100 \mathrm{~m}$ xuống sâu là khối nước lạnh ổn định, ít biến đổi.

Độ muối khối nước Biển Đông phụ thuộc trực tiếp vào điều kiện giáng thủy, quá trình bốc hơi trên biển và hoàn lưu nước của Thái Bình Dương xâm nhập vào Biển Đông. Song hoàn lưu do gió mùa đóng vai trò chính, chi phối sự phân bố độ muối của khối nước trên biển trong từng mùa. Trong mùa gió Đông Bắc, trên biển hình thành lưỡi nước lạnh có độ muối cao trên $34 \%$ o theo hướng Đông Bắc - Tây Nam. Những vùng ven bờ phía Tây Vịnh Bắc Bộ và hầu khắp Vịnh Thái Lan đều có độ muối dưới 33\%o, ở các khu vực gần cửa sông thậm chí dưới $30 \%$. Trong mùa gió Tây Nam, đồng thời cũng là mùa mưa thịnh hành trên phần lớn các vùng biển, sự phân bố độ muối phức tạp hơn. Vùng ngoài khơi Miền Trung và Nam Trung Bộ của Việt Nam duy trì độ muối cao trong cả năm. Trong mùa Đông lưỡi nước lạnh có độ mối cao 33,4\%o xâm nhập xuống sát vùng này, còn trong mùa gió Tây Nam, đường đẳng muối $33 \%$ và cao hơn cũng áp sát vào dọc bờ biển do hoạt động của nước trồi. Sự phân bố của độ muối trên Biển Đông diễn ra khá phức tạp nhưng nguyên nhân cũng khá rõ, do ăn thông với Thái Bình Dương qua các eo nên Biển Đông mang tính đại dương ở vùng biển sâu và chịu ảnh hưởng của dòng nước mặt lục địa do các sông mang ra.

Chế độ thủy triều Biển Đông cũng khá độc đáo và phức tạp, nguyên nhân là khi các sóng triều truyền từ Thái Bình Dương vào Biển Đông qua eo biển Đài Loan và lạch Bashi, bị tác động bởi điều kiện địa hình và độ sâu tạo ra đầy đủ các vùng thủy triều, bao gồm: Nhật triều đều thuần túy (đặc trưng ở khu vực Hòn Dấu, rất ít khu vực trên thế giới có loại thủy triều này), nhật triều không đều (chiếm ưu thế trên toàn Biển
Đông), bán nhật triều đều (phạm vi nhỏ khu vực cửa Thuận $A n$ ) và bán nhật triều không đều. Về biên độ đạt độ cao lớn nhất ở khu vực phía Bắc Vịnh Bắc Bộ và có xu thế giảm dần về phía Nam đến khu vực cửa Thuận An sau đó tăng dần đến khu vực Vũng Tàu và lại giảm dần về khu vực Vịnh Thái Lan.

\section{Công tác điều tra, khảo sát, thu thập dữ liệu khí tượng, hải văn trên Biển Đông}

Do vị trí trọng yếu, quan trọng về hàng hải; nguồn tài nguyên dồi dào, phong phú và đa dạng của Biển Đông nên công tác khảo sát, điều tra và nghiên cứu luôn được Nhà nước quan tâm. Nhiều đề tài, dự án và công trình nghiên cứu về Biển Đông của các cơ quan Bộ, Ngành đã đánh giá khá tổng quát về điều kiện khí tượng, hải văn của Biển Đông và tương đối chi tiết cho các khu vực ven bờ và một số đảo, quần đảo gần bờ. Số liệu thu thập ngoài khơ' đa phần thuộc các dự án liên kết điều tra hoặc thu thập từ nước ngoài (ví dụ nguồn số liệu từ NOAA). Theo tài liệu (Nguyễn Bá Xuân, 2007), số liệu nhiệt, muối của CSDL quốc gia (VODC) là 135.671 trạm đo, trong đó nhiệt độ được đo trên 123.215 trạm với 3.338 .846 số liệu; độ muối được đo trên 32.795 trạm với 495.166 số liệu. Lượng số liệu trên tương đối nhiều và cơ bản phản ánh được các quá trình nhiệt - muối của Biển Đông. Cùng với sự phát triển của khoa học công nghệ, các thiết bị khảo sát đo đạc hải văn cũng ngày càng được cải tiến để nâng cao độ chính xác và tăng độ sâu quan trắc. Chính vì vậy, việc tiếp tục khảo sát đo đạc hải văn bằng các thiết bị hiện đại vừa để chuẩn hóa số liệu đã có, vừa bổ sung vào $\mathrm{CSDL}$, làm phong phú và bảo đảm độ tin cậy của dữ liệu đầu vào cho các nhiệm vụ quan trọng luôn cần thiết và là xu thế phát triển chung của thế giới. Hiện nay ngoài các cơ quan thuộc Bộ Tài nguyên Môi trường và Viện Hàn lâm Khoa học và Công nghệ Việt Nam,...công tác điều tra, khảo sát, đo đạc 
các yếu tố hải văn trên Biển Đông còn có Bộ Quốc phòng mà trực tiếp là Quân chủng Hải quân tham gia. Số liệu thu thập được từ năm 2006 đến 2016 trên toàn Biển Đông của Quân chủng Hải quân gồm trên 121.000 trạm, trong đó các trạm có số liệu nhiệt độ là 115.034 trạm; số liệu độ muối là 26.374 trạm; số liệu vận tốc âm là 29.294 trạm và số liệu dòng chảy là 90 trạm (Hình 1).

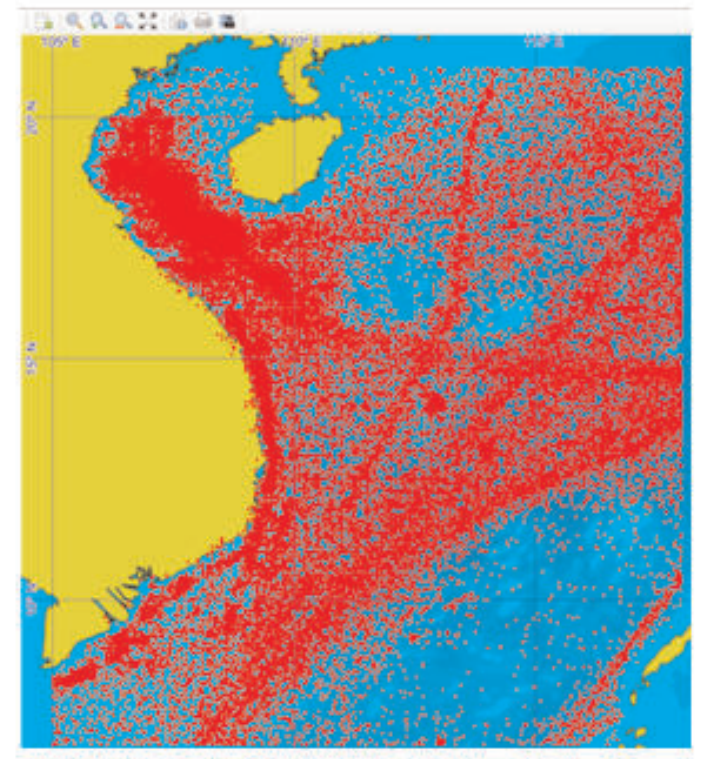

Hình 1: Phân bố các trạm có số liệu nhiệt muối và vận tốc âm

Công tác đo mới và cập nhật vào CSDL đã được triển khai từ năm 2006 đến nay. Số lượng trạm đo tính đến 2016 là 1262 trạm và được thực hiện trong nhiều đợt khảo sát. Riêng trong các năm 2015, 2016 đã tiến hành đo đạc tại 828 trạm với 28.000 số liệu nhiệt - muối và vận tốc âm tại các tầng chuẩn, trong đó có nhiều trạm thuộc Dự án điều tra cơ bản (DA47-GD2). Mật độ hệ thống trạm đo thuộc dự án tuân thủ theo đúng quy phạm quan trắc hải văn của Bộ Tài nguyên Môi trường và TCQS 04:2017/BĐ Tiêu chuẩn cơ sở, 2017. Sơ đồ một phần các trạm đo được thể hiện trên hình 2.

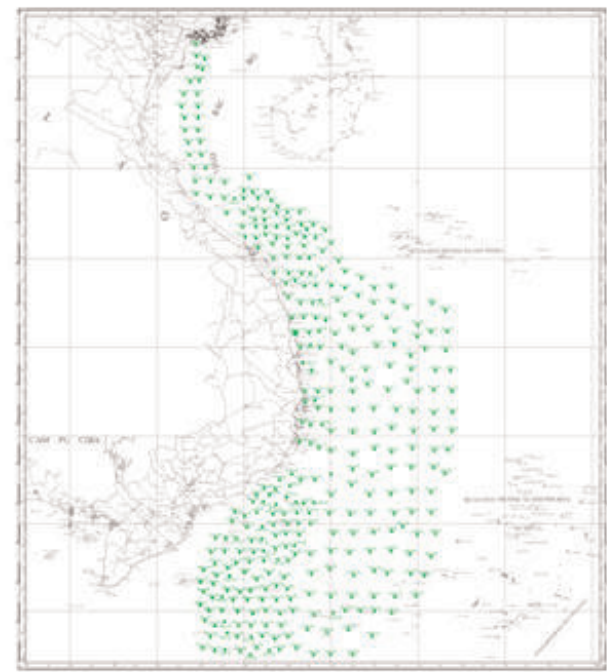

Hình 2: Sơ đồ phân bố một phần các trạm đo hải văn thuộc Dự án điều tra cơ bản

Công tác khảo sát, đo đạc được thực hiện bằng các tàu đo đạc chuyên dụng như tàu 888 (Trần Đại Nghĩa), tàu 884, tàu 883 và tàu 885 với hệ thống thiết bị hiện đại, độ chính xác cao, bao gồm:

- Thiết bị quan trắc tổng hợp sóng, dòng chảy và dao động mực nước: AWAC, Flowquest, DWR.

- Thiết bị quan trắc dòng chảy tầng sâu: Infinity, Midas ECM.

- Thiết bị quan trắc nhiệt độ, độ muối, vận tốc âm: $C^{+}{ }^{+}$,Rinko profile,SVX2, SVP, Mini SVP, AML plus.

- Thiết bị lấy mẫu chất đáy bằng ống phóng trọng lực.

- Thiết bị đo từ trường biển Sea SPY, thiết bị đo trọng lực biển...

Kết quả so sánh giữa số liệu thực đo và số liệu hiện có trong CSDL bằng Bộ phần mềm Tính toán thủy âm trong "Hệ thống tra cứu thông tin" (do Quân chủng Hải quân phối hợp với Tập đoàn Transas (Nga) thiết lập) tương đối đồng nhất và được thể hiện trên hình 3. 


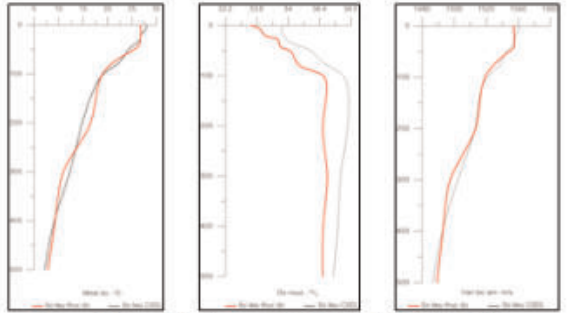

Trạm hải văn 01 có tọa độ: $12^{\circ} 28,2^{\prime} \mathrm{N}, 109^{\circ} 22,8^{\prime} \mathrm{E}$ Thời gian đo: ngày 24 tháng 6 nảm 2012

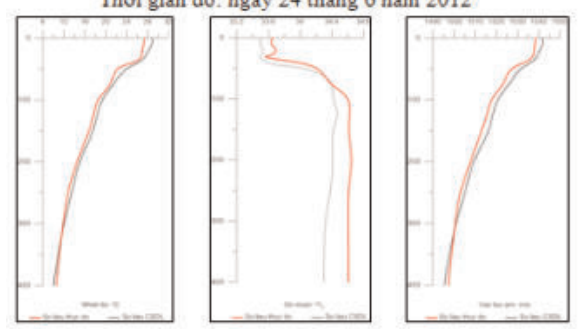

Trạm hải văn 05 có tọa độ: $12^{\circ} 24,5^{\prime} \mathrm{N}, 110^{\circ} 0,6^{\prime} \mathrm{E}$ Thời gian đo: ngày 25 tháng 6 năm 2012
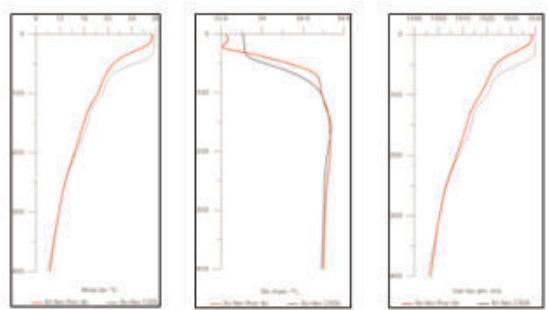

Trạm hải văn 09 có tọa độ: $12^{\circ} 16,1^{\prime} \mathrm{N}, 109^{\circ} 59,1^{\prime} \mathrm{E}$

Thời gian đo: ngày 25 tháng 6 năm 2012

Hình 3: So sánh kết quả giữa số liệu thực đo và và số liệu hiện có trong CSDL

Với nguồn số liệu trong CSDL như đã nói ở trên, việc tính toán, dự báo các yếu tố môi trường và thủy động lực là hoàn toàn có thể thực hiện được. Các tính toán xác định đặc trưng quá trình truyền âm theo phương ngang đạt kết quả tương đối chi tiết. Hình 4.1 và 4.2 thể hiện kết quả tính đặc trưng quá trình truyền âm theo mặt cắt có phương Tây - Đông và biến thiên vận tốc âm theo phương thẳng đứng tại vị trí nguồn phát với số liệu trong tháng 3 và tháng 4 từ năm 1910 đến 2015 với các thông số:

- Tọa độ 10,90N và 109,60E;

- Khoảng cách tính toán $30 \mathrm{~km}$;

- Độ sâu nguồn phát 60m;
- Độ ồn bề mặt: 0,02 Db;

- Địa hình đáy và chất đáy theo hải đồ tỷ lệ 1:1.000.

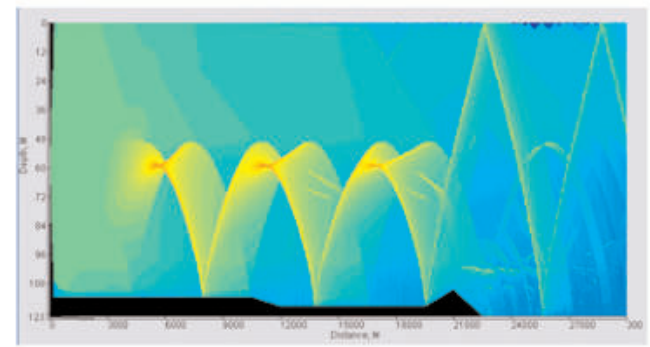

Hình 4.1: Phân bố quỹ đạo tia âm theo mặt cắt ngang

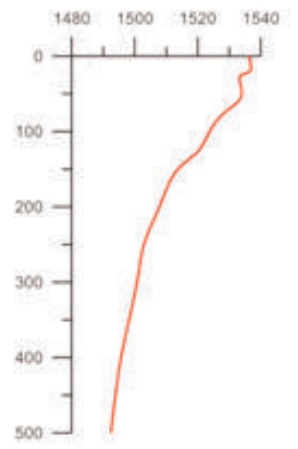

Hình 4.2: Biến thiên vận tốc âm theo phương thẳng đứng tại vị trí nguồn phát

4. Một số giải pháp nâng cao hiệu quả khảo sát, đo đạc các yếu tố hải văn trên Biển Đông

Với hệ thống các trang thiết bị khảo sát đo đạc hải văn được trang bị hiện đại và đồng bộ nêu trên, lượng dữ liệu đo đạc và thu thập được đang ngày càng lớn, có độ chính xác cao, đóng góp nhiều vào công tác nghiên cứu, lập kế hoạch tác chiến và tác chiến của các lực lượng Quân đội và sự phát triển kinh tế, xã hội của đất nước.

Tuy nhiên, cùng với quá trình hiện đại hóa các trang thiết bị khí tài thì yêu cầu về độ chính xác của số liệu thực đo cũng đặt ra ngày càng cao. Để đáp ứng yêu cầu đó cần phải thực hiện đồng bộ các giải pháp sau:

a. Thay thế và hiện đại hóa các trang 
thiết bị quan trắc:

Số liệu thu thập được thường tập trung vào giai đoạn thời tiết ổn định từ tháng 3 đến tháng 10. Số liệu các tháng mùa Đông rất ít do biển động, tàu đo chưa đủ công suất để hoạt động với gió cấp 5-6.

Số liệu tầng sâu không nhiều do hạn chế của thiết bị thu thả: Các thiết bị quan trắc tầng sâu hiện đại ngày nay như CDT+, SVP, SVX2, Rinko, Midas ECM,... có thể quan trắc đến độ sâu đến $5.000 \mathrm{~m}$. Tuy nhiên, do một số điều kiện chưa đáp ứng được nên mới chỉ tập trung khảo sát, đo đạc từ tầng mặt đến độ sâu 1000 mét, số liệu thu thập được chưa đạt độ sâu tối đa.

b. Đóng mới các tàu nghiên cứu biển theo tiêu chuẩn mới: Hiện nay, Bộ Tài nguyên và Môi trường đã và đang sử dụng 01 tàu Nghiên cứu biển, Quân chủng Hải quân đã đóng mới và đưa vào sử dụng tàu nghiên cứu biển Trần Đại Nghĩa. Thực tế cho thấy các tàu đóng mới này có ưu điểm vượt trội so với các tàu cũ, đáp ứng được yêu cầu về thời gian hoạt động lâu dài và cấp sóng- gió (từ cấp 6-7 trở lên), kết hợp với các hệ thống thiết bị khảo sát đo đạc mới, đồng bộ đã cho kết quả rất tốt.

c. Hoàn thiện các yêu cầu về tính đồng bộ, độ chính xác, độ sâu hoạt động của các thiết bị khảo sát, đo đạc trong các văn bản quy định liên quan đến việc thực hiện khảo sát, đo đạc hải văn. d. Tăng cường công tác phối hợp, hợp tác nghiên cứu, trao đổi thông tin giữa các cơ quan, bộ ngành: Cơ sở dữ liệu biển của các cơ quan bộ, ngành và của Quân chủng Hải quân tương đối lớn, có thể đáp ứng tốt các yêu cầu của công tác khảo sát nghiên cứu biển, phục vụ hoạch định các chủ trương, chính sách của Đảng và Nhà nước về biển và các nhiệm vụ của các bộ, ngành liên quan đến biển. Tuy nhiên, do chưa có sự phối hợp, hợp tác nghiên cứu và trao đổi dữ liệu giữa các cơ quan nên mỗi một nhiệm vụ, công trình triển khai mới đều tốn rất nhiều công sức, tiền của để khảo sát, đo đạc mới. Cần phải tăng cường hơn nữa công tác phối hợp, hợp tác nghiên cứu, trao đổi dữ liệu giữa các cơ quan bộ, ngành để khai thác hiệu quả các nguồn dữ liệu hiện có của các đơn vị, phục vụ cho các mục đích chuyên ngành./.O

\section{Tài liệu tham khảo}

[1]. Nguyễn Bá Xuân, 2007. Cấu trúc và đặc điểm phân bố của vận tốc âm trung bình mùa ở vùng biển Việt Nam, Tuyển tập Báo cáo Hội nghị quốc tế "Biển Đông-2007".Nha Trang -2007.

[2]. Lê Đức Tố,1999.Hải dương học Biển Đông. NXB Khoa học Kỹ thuật. Hà Nội - 1999.

[3]. TCQS 04:2017/BĐ Tiêu chuẩn cơ sở, 2017. Phương pháp khảo sát đo đạc hải dương. Nhà xuất bản Quân đội Nhân dân. Hà Nội - 2017.O

\section{Summary}

\section{Some solutions to improve the quality of surveying and measuring the elements of navigation in the East Sea}

\section{Duong Van Phong, Hanoi University of Mining and Geology}

\section{Khuong Van Long, Department of Maritime Mapping and Maritime Studies}

This article presents an overview of meteorological and marine characteristics and survey, measurement and data collection of marine elements in the South China Sea. On the basis of comparing the reliability of data stored in the database with newly collected data, the authors have proposed some solutions to improve the efficiency of surveying, measuring and collecting data. Whether the marine navy elements. $O$ 